\begin{tabular}{|ll|}
\hline $\begin{array}{l}\text { Social Work/Maatskaplike Werk Vol } 56 \text { No 4; Issue } 4 \\
\text { http://socialwork.journals.ac.za/pub }\end{array}$ & doi:http://dx.doi.org/10.15270/56-4-884 \\
\hline
\end{tabular}

EXPLORING THE BARRIERS THAT PREVENT PRACTITIONERS FROM IMPLEMENTING MOTIVATIONAL INTERVIEWING IN THEIR WORK WITH CLIENTS

Debbie Lenie Bell, Rizwana Roomaney

Motivational interviewing (MI) is an evidence-based counselling technique that is used by psychologists, doctors, nurses, midwives and social workers as an effective intervention aimed at behavioural change. Despite its efficacy, it is not commonly used in South Africa. Our aim was to explore the barriers that social and health practitioners who were trained in administering Ml experienced in implementing $\mathrm{MI}$ in their work with clients. We used a qualitative approach to explore these barriers and a phenomenological research design to explore the research question. We conducted semi-structured interviews with $15 \mathrm{Ml}$ practitioners (social workers, registered counsellors, an educational psychologist, a life coach and an addiction counsellor) who were living and working in the Western Cape and deemed competent in Ml. Our thematic analysis resulted in four broad areas being identified. These were practitioner-related factors, client-related factors, lack of continuous training and supervision, and workplace-related factors.

Ms Debbie Lenie Bell, Department of Psychology, Stellenbosch University, South Africa.

Dr Rizwana Roomaney, Department of Psychology, Stellenbosch University, South Africa.

Debbie Bell, ORCID iD: 0000-0002-4062-5190

Rizwana Roomaney, ORCID iD: 0000-0002-3585-4992

debbiebell@telkomsa.net

rizwanaroomaney@sun.ac.za

Keywords: barriers, evidence-based counselling technique, counsellor, intervention, motivational interviewing, practitioners 



\section{EXPLORING THE BARRIERS THAT PREVENT PRACTITIONERS FROM IMPLEMENTING MOTIVATIONAL INTERVIEWING IN THEIR WORK WITH CLIENTS}

\section{Debbie Lenie Bell, Rizwana Roomaney}

Ms Debbie Lenie Bell, Department of Psychology, Stellenbosch University, South Africa. Dr Rizwana Roomaney, Department of Psychology, Stellenbosch University, South Africa.

\section{INTRODUCTION}

Motivational interviewing (MI) is an evidence-based counselling technique that is used by social workers, psychologists, doctors, nurses and midwives as an effective intervention aimed at behavioural change (Barnes \& Ivezaj, 2015; Cascaes, Bielemann, Clark \& Barros, 2014; VanBuskirk \& Wetherell, 2014). MI is built on the theoretical foundation of Carl Rogers's person-centred counselling approach (Miller, 1983), but incorporates an explicitly directive style (Westra \& Aviram, 2013). The underlying principle of MI is a non-judgmental partnership between client and practitioner, where the counsellor shows respect for the client's perspectives and ideas, and fosters collaboration and power sharing. MI consists of four processes, namely (1) engaging with the client, (2) focusing by finding and keeping useful direction, (3) evoking change, and (4) planning and support (Miller \& Rollnick, 2009).

\section{LITERATURE REVIEW}

MI was originally developed for use in the field of substance addiction, but has since been employed in several other fields relating to behaviour change such as gambling (Yakovenko, Quigley, Hemmelgarn, Hodgins \& Ronksley, 2015) and orientations to corporal punishment (Holland \& Holden, 2016). MI has also been applied successfully to change behaviour in relation to smoking, alcohol abuse, HIV and diabetes management (de Vries, Joubert, Cloete, Roux, Baca, Hasken, Barnard, Buckley, Kalberg, Snell, Marais, Seedat, Parry \& May, 2016; Mertens, Ward, Bresick, Broder \& Weisner, 2014; Morojele, Kitleli, Ngako, Kekwaletswe, Nkosi, Fritz \& Parry, 2014; Parry, Morojele, Myers, Kekwaletswe, Manda, Sorsdahl, Ramjee, Hahn, Rehm \& Shuper, 2014; Satre, Leibowitz, Sterling, Lu, Travis \& Weisner, 2016;).

Despite the effectiveness of MI, studies have demonstrated that MI is underutilised (Keeley, Brody, Engel, Burke, Nordstrom, Moralez, Dickinson \& Emsermann, 2016; Lavoie, Lemiere, Blais, Labrecque, Beauchesne, Pepin, Cartier, Bacon \& Moullec, 2014; Lundahl, Moleni, Burke, Butters, Tollefson, Butler \& Rollnick, 2013). Only a few studies have examined practitioners' experience during their MI training and subsequent implementation of MI (Barnes \& Ivezaj, 2015; VanBuskirk \& Wetherell, 2014).

\section{BARRIERS TO IMPLEMENTING MI}

Studies have reported several barriers to the implementation of counselling in general and of MI in particular. These barriers often related to setting or context, insufficient training and support, practitioner experience and attitude, and client characteristics. MI interventions are mostly conducted in primary health care settings that are often very busy (Barnes \& Ivezaj, 2015; Lundahl, Moleni, Burke, Butters, Tollefson, Butler \& Rollnick, 2013; VanBuskirk \& Wetherell, 2014). Primary healthcare workers offer a wide range of interventions to high volumes of patients with limited resources and report high levels of burnout (Dookie \& Singh, 2012; Rossouw, Emsley, Suliman \& Hagemeister, 2013). MI has been implemented as an intervention in addition to daily care appointments in $75 \%$ of studies, making it a taxing exercise for practitioners (Barnes \& Ivezaj, 2015; Lundahl et al., 2013; VanBuskirk \& Wetherell, 2014).

Mastery of MI skills is essential for interventions to be effective (Miller \& Rollnick, 2002). Individuals with higher levels of professional training delivered more effective MI than individuals with no tertiary 
education (VanBuskirk \& Wetherell, 2014). The reason for this difference has not been studied, but may be related to the structure of training programmes. Similarly, MI interventionists from a counselling background are more proficient in delivering MI interventions than interventionists who do not see MI as part of their professional role (Darnell, Dunn, Atkins, Ingraham \& Zatzick, 2016). Studies indicate that baseline MI skill levels are the strongest predictors of both pre-supervision and post-supervision counselling performances when compared to post-training supervision (Carpenter, Cheng, Smith, Brooks, Amrhein, Wain \& Nunes, 2012; Dewing, Mathews, Cloete, Schaay, Shah, Simbayi \& Louw, 2013; Mash, Baldassini, Mkhatshwa, Sayeed \& Ndapeua, 2008).

The structure of a training programmes may play a role in the successful implementation of MI. Training should be sufficiently long enough to allow for trainees to grasp the intricacies of the theory and incorporate practical methods such as role plays and peer observations (Carpenter et al., 2012; Mash, Rhode, Zwarenstein, Rollnick, Lombard, Steyn \& Levitt, 2014). While manuals are an important tool in training, they should not be rigidly structured, as this may make implementation cumbersome as they do not take agency of clients into account (Dewing et al., 2013). Follow-up workshops and regular supervision and feedback are necessary to ensure the successful application of MI (Miller \& Rose, 2009). Prolonged contact sessions, regular feedback and supervision sessions could enhance the interventionist's MI skills (Dewing et al., 2013; Söderlund, Madson, Rubak \& Nilsen, 2011).

Several personal factors that impede MI have been identified. Age has been identified as a factor, as younger practitioners have favoured evidence-based practices such as MI more than the older therapists have (Amodeo, Lundgren, Cohen, Rose, Chassler, Beltrame \& D'Ippolito, 2011). Attitudes towards a therapeutic approach were found to be a predictor of successful implementation of the approach. This applies to both MI (Storholm, Ober, Hunter, Becker, Iyiewuare, Pham \& Watkins, 2017) and other evidence-based therapies (Amodeo et al., 2011; Jordan, Bowers \& Morton, 2016; Lundgren, Chassler, Amodeo, D'Ippolito \& Sullivan, 2012; McCarty, Fuller, Arfken, Miller, Nunes, Edmundson, Copersino, Floyd, Forman, Laws, Magruder, Oyama, Prather, Sindelar \& Wendt, 2007; Tacia, Biskupski, Pheley \& Lehto, 2015).

Finally, studies show that factors related to clients can impact on the efficacy of MI training. These factors include client resistance, psychiatric disorders treatment (Horsfall, Cleary, Hunt \& Walter, 2009) and cognitive ability (Carroll Chapman \& Wu, 2012; Lundahl \& Burke, 2009).

MI may have tremendous potential in under-resourced settings such as South Africa, but it is not a commonly used intervention. Training for MI in the Western Cape is offered as a short course at two universities. There is very little follow up on the implementation of MI following training.

\section{METHODOLOGY}

\section{Aim of study}

The aim of this study was to determine the barriers to implementing MI in South Africa from the perspective of practitioners who received training and achieved competency in MI. A qualitative approach was used to explore these barriers as this approach would allow for a deeper understanding of these barriers (Creswell, 2007).

\section{Research design}

A phenomenological research design was used to explore the research question. Data were collected using semi-structured interviews.

\section{Study setting}

This study was conducted among social and health practitioners living and working in the Western Cape, South Africa. Participants were trained in MI and employed in various settings such as local government facilities and private treatment institutions. 


\section{PARTICIPANTS}

\section{Inclusion and exclusion criteria}

In keeping with the aim of the research, only practitioners who were trained in MI and achieved competency were allowed to participate in the study. In addition, participants had to have achieved MI competency at least 6 months prior to being interviewed to allow them sufficient time to have been able to practise MI with clients. Participants also had to be employed as social and/or health practitioners. Both males and females that could speak English or Afrikaans were considered eligible to participate.

\section{Participant recruitment}

We used two methods to recruit participants. Initially purposive sampling was used to recruit participants for the study. Participants were recruited from a university that offers MI training to professionals. We accessed the contact details of practitioners who completed a MI training course and who achieved competency, and invited them to participate in the study Only four practitioners agreed to participate in the study using this recruitment method and we then resorted to snowball sampling. Recruitment ceased when no new information emerged during interviews.

\section{PARTICIPANT CHARACTERISTICS}

The participants in this study were 15 practitioners who had received training in MI. Thirteen (13) participants were women and 2 were men. Participants' ages ranged from 27 to 64 years (average age = 37 years). Most of the participants were social workers, followed by registered counsellors, an educational psychologist, a life coach and an addiction counsellor. Five social workers, the psychiatric nurse and the addiction counsellor worked at structured in-patient treatment centres. Social workers also worked at a non-governmental organisation in private practise and governmental programmes. Both registered counsellors worked in academic settings. The educational psychologist worked at a high school and the life coach ran her private practice, where she worked mostly with postgraduate students enrolled for their Masters' programmes.

Participants reported different degrees of experience in MI, with some participants reporting having used MI only for one year, while others had used MI for up to 10 years. The majority of the interviews were conducted in English, while the rest were conducted in Afrikaans. Some of the participants completed their MI training through Stellenbosch University as a short course, while the others were trained in MI as a module as part of the postgraduate course in addiction at Stellenbosch University or at the University of Cape Town.

\section{Data collection}

Interviews were conducted with the participants at their convenience in private settings. Interviews were conducted in English or Afrikaans. The semi-structured interviews were informed by an interview schedule that consisted of 10 open-ended questions. The interviews lasted approximately 45 minutes to an hour and were audio recorded and transcribed.

\section{Data analysis}

Transcribed data were entered into Atlas.ti data management software and analysis was conducted using the program. A thematic analysis was conducted to analyse the interview. We used the guidelines provided by Clark and Braun (2013) to identify patterns and themes within the data to interpret and to make sense of it (Clark \& Braun, 2013).

Lincoln and Guba (1985) propose that qualitative research be evaluated by assessing its credibility, transferability, dependability and confirmability. We participated in prolonged engagement with key stakeholders throughout the study and undertook peer debriefing to improve the credibility of the study. Furthermore, a great deal of time during the interviews was used to build rapport with participants to enable them to feel comfortable about sharing their experiences. We provided a thick description of our findings to enhance transferability. Dependability was sought by discussing each interview and ensuring that there was consensus on the coding and interpretation of interviews. Reflexivity was 
encouraged throughout the research process and detailed notes on coding are available as an audit trail as steps toward confirmability.

\section{Ethical considerations}

Ethical approval for the study was granted by the Research Ethics Committee at Stellenbosch University before the study commenced. Written informed consent was obtained from participants. Participation was voluntary and participants were allowed to withdraw from the study. Written permission was obtained from participants to audio-tape the interviews. Free counselling services were made available to participants if the interviews resulted in any distress. Confidentiality was maintained and pseudonyms were used when transcribing the interviews and reporting the findings. The data are safely stored, with only the researchers having access to it and will be destroyed after five years after completion of the study.

\section{FINDINGS}

Our findings are organised in four overarching themes, with each containing a number of sub-themes that represent the barriers to implementing MI. We named these themes as follows: (1) practitionerrelated factors, (2) client-related factors, (3) training and professional support, and (4) workplacerelated factors.

\section{Practitioner related factors}

Several factors relating to the practitioners were identified that impeded the practice of MI. These included the need for a therapeutic paradigm shift, lack of confidence in implementing MI and attitudes toward MI.

\section{Therapeutic paradigm shift}

A paradigm shift is a cognitive shift that results in a change in perspective (Amodeo et al., 2011). In MI the therapeutic relationship can be described as a partnership. Participants stated that the process of understanding MI required a cognitive shift from wanting to be in control to having a partnership with the client. Participants reported that they found it challenging to shift from the directive counselling approaches that they relied on heavily as social workers and registered counsellors to MI, as it is a more non-directive approach. Participants identified the paradigm shift as a barrier when they initially started with MI. Participants reported that they recognized some of the principles from previous counselling theories, such as building rapport and empathy, within the theory of MI. According to some participants, using MI was quite difficult in the beginning with specific techniques of MI such as keeping quiet, asking open-ended questions, listening and reflecting. Many stated that they tended to work from the perspective of an expert having the solution for the client's problems. Furthermore, they reported that they struggled to elicit solutions and reflections from their clients, as is required with MI.

For these reasons, participants embraced directive counselling approaches, which placed them in an authoritative position. Practitioners reported that they tried to control the process of change rather than facilitating the process of the change, and that they found it difficult to refrain from giving advice and allowing the client to solve their own problems. Neil, a social worker working in an addiction treatment centre stated the following:

So, MI brought a switch, actually a kind of deviation of what we've learn and how we've been taught. So it's now taking the back seat, and allowing the client to take the front seat. So it's now no more your pace but on the pace of the client. So a lot of paradigm shifts came about with MI which was not an easy one for a social worker like me that for many years couldn't, like I said, had to be in the driving seat for clients.

Engaging in paradigm shifts is not easy, as therapists in other studies also indicated that making these shifts was difficult (Amodeo et al., 2011; Jordan et al., 2016). Interviews with nurses who received training in MI revealed that this paradigm shift was a challenge for them, as it did not align with the 
authoritarian position that they usually took in their work (Söderlund, Nilsen \& Kristensson, 2008). Proponents of MI, Rollnick, Miller and Butler (2007), described MI as a difficult and complex clinical skill and concluded that one can only be competent if skills and techniques are intentionally refined during the practitioners' career. However, as indicated in research, therapists' opinions towards the approach changed after they became familiar with practising MI (Amodeo et al., 2011; Jordan et al., 2016). This barrier can therefore be regarded as a temporary barrier that can be overcome with sufficient training, support and experience.

\section{Lack of confidence}

Practitioners' lack of confidence in their ability to implement MI was noted as a barrier to the implementation of MI. Some participants reported that they felt insecure about their competence in applying MI and were unsure about the efficacy of their application of MI. This lack of self-confidence was associated with a lack of knowledge about MI and resulted in participants reverting to counselling techniques that they were familiar with instead of MI. The lack of knowledge may have related to perceived inadequate training. In the following statement, Peter described the impact of a lack of counselling skills on confidence to practice MI.

There is a few obstacles that I would like to highlight from my perspective. The first was some personal stuff, some confidence issue. Did I have the confidence to do MI well? Were I doing it right? So with all the training, considering the addiction training and the short course training, we had some feedback but for me that wasn't enough to give me the confidence to practise it without anxiety.

The finding relating to practitioner confidence in practising MI relates to self-efficacy. A lack of knowledge can act as a barrier to developing self-efficacy and decrease motivation (Storholm et al., 2017). In a longitudinal qualitative study among workers in a primary care setting, participants initially described self-efficacy as a medium to large barrier to care, but over time reconsidered the impact as small to medium (Storholm et al, 2017). It is likely that additional training and support may improve perceived self-efficacy and lead to improved practice of MI.

\section{Attitudes towards MI}

Most participants reported that they had a positive attitude towards the application of MI. These practitioners stated that they enjoyed learning about MI and recognised the benefits of MI for themselves and their clients. However, participants reported that practitioners with negative attitudes toward MI did not practise MI correctly.

Participants who preferred an authoritative approach in their work with clients were resistant to the principles of MI and reported a negative attitude towards MI. Some participants reported that they relied on the unequal power dynamics with participants to effect change in their clients as this worked for them in the past. Other participants indicated that their profession often relied on uneven power dynamics between practitioners and clients. For example, Sarah, a nurse, stated that the approaches of MI were in opposition with nursing practices. She also stated that traditional nursing teaching programmes positioned nurses as experts in relation to their clients. Another similar factor that played a role in the development of negative attitudes towards MI was the practitioner's previous experience with being counselled. For example, one participant who had a history of drug addiction and worked in the field of addiction stated that he regarded giving advice as more effective than exploring solutions for the problem with the client. He stated that MI focused too much on positive reinforcement, which did not allow him to be confrontational, which he deemed necessary for behaviour change. In the following interview extract, Manie conveys his thoughts on the most effective techniques to effect behaviour change:

I prefer to speak from my own experience, or to give the type of advice. If they're not doing that, it's up to me to point that out to them... It's got to be a little more interjecting, cutting to the chest, what about this and very often I am not liked and I've learnt to be fine with that. 
The way I earn their respect more, the clients respect more and then I share from my personal... you know, experience. I am in recovery ... and I found that, that helps.

This negative attitude toward MI was labelled staff resistance in a study that compared barriers to evidence-based therapy between practitioners using four different approached, including MI (Amodeo et al., 2011). Interestingly, staff resistance was only mentioned as a barrier to MI and not identified as a barrier to any of the other forms of therapy in the study (Amodeo et al., 2011). This may mean that other types of therapy, such as cognitive behavioural therapy, are more acceptable to practitioners. Practitioner resistance may also have been due to MI's unique approach to the practitioner-client relationship. Other studies also reported that negative attitudes toward evidence-based practices impacted negatively on their implementation (Carpenter et al., 2012; Decker \& Martino, 2013). This finding in our study suggests that the attitude toward MI is key to implementation, as those with positive attitudes towards MI enjoyed using MI in their work with clients, whereas those who expressed negative attitudes towards MI did not use the approach. Assessing attitudes towards the approach may therefore be useful in identifying practitioners who will benefit from MI training.

\section{Client-related factors}

Client-related factors are the barriers that practitioners experienced originating from clients that impeded the implementation of MI. These barriers were located both within the client and the broader community where clients resided. This theme consists of several sub-themes namely the personal context, lack of family support, psychiatric comorbidity and cognitive ability, and client resistance. It is important to note that these are factors that practitioners regarded as barriers to MI, not factors that clients regarded as barriers, as clients were not interviewed. Furthermore, many of these barriers can be regarded as barriers to therapeutic interventions in general, and may not related to MI specifically.

\section{Personal context}

Participants reported that the circumstances that they worked in had a direct impact on the way they counselled their clients. Many reported that they worked in communities with difficult socio-economic circumstances. Several participants also reported that their clients lived in poverty and did not always have access to basic resources such as food and money. Participants explained that many of their clients would rather use their money to buy food than spend it on transport to the facility for counselling, because most of them were unemployed. Practitioners reported that their clients did not attend their counselling sessions regularly. This poor attendance was considered an important factor as it limited the time available time for their intensive counselling sessions.

The role that socio-economic circumstances play in clients' lives has also been highlighted in previous research. Low-income clients struggle to access and maintain mental health services because of logistical issues such as transport, work and childcare (Kim \& Cardemil, 2012; Krupnick \& Melnikoff, 2012; Organista, Muñoz \& González, 1994). Low-income clients may also prematurely terminate therapy (Organista et al., 1994). This is understandable when one considers Maslow's hierarchy of needs (1943), which states that basic physical needs must first be met before higher-level needs such as psychological needs can be met. Considering the basic needs of clients is an important consideration in resource-strained settings. It indicates that the context should first be assessed for suitability prior to implementing MI and that additional support may be required by clients in order to facilitate MI.

\section{Lack of family support}

Several participants identified clients' families as sources of hindrance to the MI process because of lack of support. The participants felt that their clients' families lacked knowledge and insight into understanding the psychological processes of behaviour change. The lack of family support was especially challenging when working with adolescent clients, where parents indicated a need to control the therapeutic process and outcomes, and were at times impatient with the process of MI counselling. 
Participants stated a lack of understanding of the therapeutic process by family members was another barrier to the implementation of MI. Participants stated that when their clients experienced therapy, they often moved ahead of their families, leading to a lack of support from family members. Noel, an addiction counsellor, stated that family members should be informed of the processes of the cycle of change in order to move along with the client.

I think of course the lack of insight from families [is a barrier], I do not think it is only the client that should go through the cycle of change. I think their families should also.

We did not find any studies that identified lack of family support as a barrier to MI or evidence-based practice. However, a recent systematic review of barriers to and facilitators of EBPs concluded that family commitments were a barrier to treatment, but this was not a finding of the current study (Mathieson, Grande \& Luker, 2019). This finding may therefore be considered a unique contribution to the literature. Furthermore, it may further illustrate the importance of family within the current context and the need for a systems-based approach.

\section{Psychiatric comorbidity and cognitive ability}

Some participants reported that they worked with clients who were diagnosed with psychiatric conditions such as bipolar mood disorder or schizophrenia in addition to the substance use disorder that they were in therapy for. Practitioners reported that they experienced it challenging to work with these clients, as they required prolonged therapy and became resistant to therapy when they did not adhere to their prescription medication. Clients with substance-induced psychosis were particularly challenging to engage and focus on during therapy, because most participants that were not trained in clinical psychology or psychiatry to manage patients with psychiatric features. In the following comment Sarah, a psychiatric nurse, recalls her engagement with a dual diagnosis client.

So, I had one client who, I wanted to try motivational interviewing with because he was not very compliant, starting to drop [disengage], he was very conflicting about taking his meds. He didn't feel that the diagnosis of psychosis, his condition, was fair. He was quite resistant to psychiatry and was resistant to not using [drugs] and he was pretty resistant to come here, but I found with the guys ... have much more mental illness, [this] is like a continuing factor.

Several of the participants reported that the different intellectual or cognitive abilities of the clients also played a large role in applying MI. Some participants reported that a few of their clients lacked insight into their problems and lacked the language to be able to convey their internal thought processes. One participant stated that in such cases she opted for a more direct approach than that used in MI.

Other studies also reported the challenges in working with such clients, but state that clients who adhere to taking their medication are amenable to MI (Horsfall et al., 2009; Moore, 2015; Storholm et al., 2017). According to these researchers, medication may stabilise clients, thereby increasing their self-efficacy and ability to comply with treatment (Moore, 2015); however, the practitioners in our study reported adherence to medication an issue. While some participants in the current study reported that they found it challenging to implement MI among clients with intellectual or cognitive challenges, other participants found ways in which to do so. Other researchers have indicated that it is possible to implement MI among clients with intellectual and cognitive challenges by adopting a multidisciplinary approach and by allowing for more time during sessions to allow clients to reflect and by repeating questions (Horsfall et al., 2009). MI training programmes may benefit practitioners by including a component relating to treating clients with dual diagnosis.

\section{Client resistance}

The final client-related factor that impeded the implementation of MI in this study was resistance. Resistance in this context refers to a client's refusal to accept that he/she has a problem and is unwilling to change. Some participants reported that they felt that resistance from a client was a challenge for MI, while others reported that MI worked well with clients who were resistant. 
Motivation for attending counselling was an important factor in client resistance. Clients who were directed by their families to attend therapy, such as in the case of clients attending addiction programmes, were often resistant to MI. Similarly, participants reported that clients who attended court-mandated counselling were also resistant and that they struggled to practise MI with them. Amy, a social worker with eight years of MI experience, who worked in a treatment centre for adults, made the following statement:

When you worked with clients that had been committed, or are referred by court process and the resistance and reluctance is really always a huge challenging factor. Once one have gotten through that to diminish resistance, the whole process becomes more effective.

The finding that client resistance was a barrier to MI implementation was not surprising as it was reported in several studies (Amodeo et al., 2011; Horsfall et al., 2009; Westra, 2004). In the current study resistance was a common feature among clients who were forced by family members or mandated by court to attend counselling. The resistance was therefore expected. Some participants reported that they were able to work with resistant clients. It may be useful to investigate why some practitioners are better able to implement MI with resistant clients than others are.

\section{Lack ot continuous training and support}

Two factors pertaining to training and support were identified as barriers to the implementation of MI among participants. These factors relate to the impact of previous qualifications and post-training supervision.

\section{Impact of previous qualification on $\mathrm{MI}$}

Participants possessed a broad range of qualifications. Most had degrees with some form of previous counselling training. However, some did not have previous professional counselling training. The majority of respondents reported that their limited prior counselling training was useful for the understanding and the application of MI. Their prior training allowed them to recognise certain concepts used in MI. The participants stated that their previous counselling knowledge assisted them in differentiating between MI and other counselling approaches. Their respective qualifications assisted them to understand the new MI skills and how to integrate these skills with their existing skills. Noel, a social worker working at an alcohol detox facility, made the following statement:

For me, even if you think about other counselling styles, there has to be some background and some training. Luckily some of my training was person-centred, which is very similar or close to MI; this laid a good foundation to grasp some of the concepts and it also helped to develop my style and that's why I think MI got me hooked.

However, other participants reported that their qualifications did not contribute to their understanding of MI. Some of these participants were trained in counselling, but reported that they did not learn about MI during their formal training and this delayed their ability to practise it. Other participants did not have any counselling qualifications and struggled to understand MI.

Previous studies demonstrate that professional counsellors trained in MI were better able to implement MI than non-professional counsellors with training in MI (Carpenter et al., 2012; Dewing et al., 2013; VanBuskirk \& Wetherell, 2014). Similarly, non-professional counsellors in our study reported difficulty in implementing MI in their practices. They chose to do counselling from their own experience. This finding indicates that MI training may be better suited to those with prior counselling training than those with no previous counselling training. Alternatively, bridging courses may be beneficial to those interested in learning MI but who do not have a background in counselling education. 


\section{Post-training supervision}

As previously mentioned, a lack of confidence in their ability to practise MI was a barrier to its implementation. Almost all the participants emphasized the importance of supervision and support after their MI training. Participants reported the need for supervision to assist them in applying MI correctly, because it was a new approach to them. They reported that the lack of confidence in their ability to apply MI would have been addressed, if they had had supervision after their training. Many stated that they needed guidance to stay motivated to use MI and to be more effective in their practice. However, the participants reported limited or no support and supervision from the trainers after the MI training and at their workplaces. Some participants stated that their supervisors/managers at their workplaces were not trained in MI and therefore not equipped to assist them or provide guidance. Ellen, a social worker, described her need for post-supervision training in the following extract:

I did get a supervisor in this environment but she's not MI trained and it's not going to be a place where I'm going to get support around that because I'm already busy to look for a supervisor who is also passionate about MI.

Several studies suggest that maintenance of MI skills is important but requires continuous training, supervision and support (Amodeo et al., 2011; Lundgren et al., 2012; Petersen et al., 2007; Storholm et al., 2017). Other studies reported that a lack of support and supervision after training was a barrier to the implementation of evidence-based practices (Carpenter et al., 2012; Dewing et al., 2013; Forsberg, Ernst, \& Farbring, 2010; Malan, Mash \& Everett-Murphy, 2015). The barriers relating to continuous training and support provide an indication of the important role that training plays in the implementation of MI. Participants suggest that supervision would benefit their practice of MI and training programmes could include a supervision component either prior to accreditation or after.

\section{Workplace-related factors}

Workplace-related factors refer to barriers in the work environment that participants reported hindered their implementation of MI interventions. Two workplace-related factors were discussed by participants, namely management as a barrier, and time as a barrier.

\section{Management as a barrier}

One of the reported barriers was that management expected certain performance outcomes from the participants, which did not align with the application of MI. Participants reported that management did not allow adjustments to the structure of their programmes in order to accommodate MI as a counselling approach within these programmes. Participants stated that they felt as though their managers focused on quantitative outcomes and not on the importance of the process during the intervention. For example, counsellors were required to see a certain number of clients per month. Participants reached the expected total number of clients when they used more directive techniques than prescribed by MI, as this required fewer contact sessions and less interaction with clients than MI did. Participants stated that this resulted in them resorting to using more direct techniques, thereby not adhering to MI. Furthermore, participants reported that they did not feel supported by their managers to learn about MI by funding training and providing sufficient leave for them to attend training. Programme managers play a key role in deciding which interventions are used. Participants reported that their managers were not trained in MI and may not have been able to understand the conditions required to implement MI. Therefore, even if they recommended that practitioners receive training in MI, they may have acted as a barrier towards the implementation of MI. In the following statement Marie shares some of the workplace-related challenges that she experienced.

If your management doesn't understand MI, and you don't get support from them, it's going to be a major obstacle in your service delivery. [translated from Afrikaans]

These results about the workplace barriers are consistent with those mentioned in previous research (Amodeo; 2011; Barnes \& Ivezaj 2015; Lundgren et al., 2012; Storholm et al., 2017). The need for enough trained staff was reported in these studies. It was therefore difficult for unequipped staff to 
adhere to the organisations' policies and procedures. Malan et al. (2015) confirmed the need for more staff that understood the home language of the client, a lack of resources, administrative problems and training for not just the counsellors, but also for other staff members who had contact with clients. Participant in our study did not mention language as a barrier and this is unusual considering the multicultural setting where the study was located. The general consensus among participants was that it was challenging to promote behaviour change with clients with the constraints within which their organisations worked.

\section{Time as a barrier}

Most of the participants stated that the time allocated in their structured programmes was not sufficient for them to use MI as their preferred counselling method. Some participants stated the duration for individual sessions was approximately 15-30 minutes per person and that this was not enough time to implement MI. Participants reported that the structured programmes within which they worked consisted mostly of group therapy sessions, which they thought was not amenable to MI. Participants stated that they required more time to conduct individual sessions with clients for MI.

The second obstacle was when I was working in a NGO ... where they were quite focus on numbers, you know, and quantity of clients ... that was difficult for me to purely implement MI because it sometimes can be a little bit slower approach which take a little bit more time. And if I had to implement purely MI, I would maybe not have reach my numbers according to what was expected of me, you know. So that was another challenge for me.

This barrier was also reported by many other studies (Amodeo 2011; Barnes \& Ivezaj 2015; Dewing et al., 2013; Lundgren et al., 2012; Malan et al., 2015; Petersen et al., 2007 Storholm et al., 2017). These studies reported the need for more time spent on training, the adjustment of the time allocation in the treatment programme, the importance of time allocated for more supervision and support and a lack of time for implementation because of a big workload and a lack of staff. Given the resource-constrained environment that those who offer MI work in, it is not surprising that these organisational barriers were highlighted. Prior to sending staff for MI training, organisations should consider whether they have the capacity to implement MI.

\section{CONCLUSION}

Several barriers that prevented practitioners' from using motivational interviewing effectively as a counselling approach with their clients were identified in the current study. These are multi-levelled and are located within the client, practitioner, training programmes and context where counselling occurs. MI is an effective tool for behaviour change, but this study indicates that each of these levels should be assessed prior to implementing MI in order to determine if MI is feasible within the proposed setting.

The main limitation of the study was that it only explored practitioners' experiences of barriers to MI and not the perspectives of programme managers and other staff where the practitioners worked. Including these individuals in future research will result in a more holistic understanding of the barriers to MI. Furthermore, future studies could explore barriers that clients experienced in their MI counselling sessions as these experiences might be different from those of the social and health practitioner. A second limitation relates to the sampling size and that participants were recruited only from the Western Cape. Training programmes in other provinces in South Africa may offer more support to those who are trained than the programme we worked with to recruit participants.

Several recommendations for practice stem from this study. First, organisations using or planning to use MI should determine whether their practitioners are open to practising MI and have the prerequisite training that will enhance their MI skills. Second, the inclusion of mandatory supervision after MI training may enhance MI practitioner skills over time and build confidence in their ability to implement MI. Finally, managers should assess whether implementing MI is feasible within their organisations and whether it is appropriate for the clients who are being served. 


\section{REFERENCES}

AMODEO, M., LUNDGREN, L., COHEN, A., ROSE, D., CHASSlER, D., BELTRAME, C. \& D'IPPOLITO, M. 2011. Barriers to implementing evidence-based practices in addiction treatment programs: Comparing staff reports on motivational interviewing, adolescent community reinforcement approach, assertive community treatment, and cognitive-behavioral therapy. Evaluation and Program Planning, 34:382-389.

BARNES, R.D. \& IVEZAJ, V. 2015. A systematic review of motivational interviewing for weight loss among adults in primary care. Obesity Reviews, 16(4):304-318.

CARPENTER, K.M., CHENG, W.Y., SMITH, J.L., BROOKS, A.C., AMRHEIN, P.C., WAIN, R.M. \& NUNES, E. V. 2012. "Old dogs" and new skills: How clinician characteristics relate to motivational interviewing skills before, during, and after training. Journal of Consulting and Clinical Psychology, 80(4):560-573.

CARROLL CHAPMAN, S.L. \& WU, L.T. 2012. Substance abuse among individuals with intellectual disabilities. Research in Developmental Disabilities, 33(4):1147-56.

CASCAES, A.M., BIELEMANN, R.M., CLARK, V.L. \& BARROS, A.J.D. 2014. Effectiveness of motivational interviewing at improving oral health: a systematic review. Revista de saude publica, 48(1):142-53.

CRESWELL, J.W. 2007. Qualitative inquiry and research design: Choosing among five approaches. (2nd ed). SAGE Publications, Inc.

DARNELL, D., DUNN, C., ATKINS, D., INGRAHAM, L. \& ZATZICK, D. 2016. A randomized evaluation of motivational interviewing training for mandated implementation of alcohol screening and brief intervention in trauma Centres. Journal of Substance Abuse Treatment, 60:36-44.

DECKER, S.E. \& MARTINO, S. 2013. Unintended effects of training on clinicians' interest, confidence, and commitment in using motivational interviewing. Drug and Alcohol Dependence, 132(3):681.

DE VRIES, M.M., JOUBERT, B., ClOETE, M., ROUX, S., BACA, B.A., HASKEN, J.M., BARNARD, R., BUCKLEY, D. 2016. Indicated Prevention of foetal alcohol spectrum disorders in South Africa: Effectiveness of case management. International Journal of Environmental Research and Public Health, 13(1):76.

DEWING, S., MATHEWS, C., CLOETE, A., SCHAAY, N., SHAH, M., SIMBAYI, L. \& LOUW, J. 2013. From research to practice: Lay adherence counsellors' fidelity to an evidence-based intervention for promoting adherence to antiretroviral treatment in the Western Cape, South Africa. AIDS and Behavior, 17(9):2935-2945.

DOOKIE, S., \& SINGH, S. 2012. Primary health services at district level in South Africa: a critique of the primary health care approach. BMC Family Practice, 13(1):67.

HOLLAND, G.W.O. \& HOLDEN, G.W. 2016. Changing orientations to corporal punishment: A randomized, control trial of the efficacy of a motivational approach to psycho-education. Psychology of Violence, 6(2):233-242.

HORSFALL, J., CLEARY, M., HUNT, G.E. \& WALTER, G. 2009. Psychosocial treatments for people with co-occurring severe mental illnesses and substance use disorders (Dual diagnosis): A review of empirical evidence. Harvard Review of Psychiatry, 17(1):24-34.

JORDAN, P.J., BOWERS, C.A. \& MORTON, D. 2016. Barriers to implementing evidence-based practice in a private intensive care unit in the Eastern Cape. Southern African Journal of Critical Care, 32(2):50.

KEELEY, R.D., BRODY, D.S., ENGEL, M., BURKE, B.L., NORDSTROM, K., MORALEZ, E., 
DICKINSON, L.M. \& EMSERMANN, C. 2016. Motivational interviewing improves depression outcome in primary care: A cluster randomized trial. Journal of Consulting and Clinical Psychology, 84(11):993-1007.

KIM, S. \& CARDEMIL, E. 2012. Effective psychotherapy with low-income clients: The importance of attending to social class. Journal of Contemporary Psychotherapy, 42(1):27-35.

KRUPNICK, J.L. \& MELNIKOFF, S.E. 2012. Psychotherapy with low-income patients: Lessons learned from treatment studies. Journal of Contemporary Psychotherapy, 42(1):7-15.

LAVOIE, K.L., LEMIERE, C., BLAIS, L., LABRECQUE, M., BEAUCHESNE, M.-F., PEPIN, V., CARTIER, A., BACON, S. 2014. Efficacy of brief motivational interviewing to improve adherence to inhaled corticosteroids among adult asthmatics: results from a randomized controlled pilot feasibility trial. Patient Preference and Adherence, 8:1555.

LINCOLN, Y. \& GUBA, E. 1985. Naturalistic inquiry. Newbury Park, California: Sage.

LUNDAHL, B. \& BURKE, B.L. 2009. The effectiveness and applicability of motivational interviewing: a practice-friendly review of four meta-analyses. Journal of Clinical Psychology, 65(11):1232-1245.

LUNDAHL, B., MOLENI, T., BURKE, B.L., BUTTERS, R., TOLLEFSON, D., BUTLER, C. \& ROLLNICK, S. 2013. Motivational interviewing in medical care settings: A systematic review and meta-analysis of randomized controlled trials. Patient Education and Counselling, 93(2):157-168.

LUNDGREN, L., CHASSlER, D., AMODEO, M., D'IPPOLITO, M. \& SUlLIVAN, L. 2012. Barriers to implementation of evidence-based addiction treatment: A national study. Journal of Substance Abuse Treatment, 42(3):231-238.

MALAN, Z., MASH, R. \& EVERETT-MURPHY, K. 2015. Qualitative evaluation of primary care providers experiences of a training programme to offer brief behaviour change counselling on risk factors for non-communicable diseases in South Africa. BMC Family Practice. 16(1):101.

MASH, R., BALDASSINI, G., MKHATSHWA, H., SAYEED, I. \& NDAPEUA, S. 2008. Reflections on the training of counsellors in motivational interviewing for programmes for the prevention of mother to child transmission of HIV in sub-Saharan Africa. South African Family Practice, 50(2):5359.

MASH, R.J., RHODE, H., ZWARENSTEIN, M., ROLLNICK, S., LOMBARD, C., STEYN, K. \& LEVITT, N. 2014. Effectiveness of a group diabetes education programme in under-served communities in South Africa: a pragmatic cluster randomized controlled trial. Diabetic Medicine, 31(8):987-993.

MASLOW, A.H. 1943. A theory of human motivation. Psychological Review, 50(4):370-396.

MATHIESON, A., GRANDE, G. \& LUKER, K. 2019. Strategies, facilitators and barriers to implementation of evidence-based practice in community nursing: A systematic mixed-studies review and qualitative synthesis. Primary Health Care Research and Development, 20.

MCCARTY, D., FULlER, B.E., ARFKEN, C., MILlER, M., NUNES, E. V., EDMUNDSON, E., COPERSINO, M., FLOYD, A. 2007. Direct care workers in the National Drug Abuse Treatment Clinical Trials Network: Characteristics, opinions, and beliefs. Psychiatric Services, 58(2):181-190.

MERTENS, J.R., WARD, C.L., BRESICK, G.F., BRODER, T. \& WEISNER, C.M. 2014. Effectiveness of nurse-practitioner-delivered brief motivational intervention for young adult alcohol and drug use in primary care in South Africa: A randomized clinical trial. Alcohol and Alcoholism, 49(4):430-438.

MILLER, W.R. 1983. Motivational interviewing with problem drinkers. Behavioural Psychotherapy, 11(2):147-172. 
MILLER, W. \& ROLLNICK, S. 2002. Motivational interviewing: Preparing people for change, PsycNET. (2nd ed). The Guilford Press. [Online] Available: https://psycnet.apa.org/record/200202948-000 [Accessed: 11/09/2019].

MILLER, W.R. \& ROLLNICK, S. 2009. Ten things that motivational interviewing is not. Behavioural and Cognitive Psychotherapy, 37(2):129-140.

MILLER, W.R. \& ROSE, G.S. 2009. Toward a theory of motivational interviewing. The American Psychologist, 64(6):527-37.

MOORE, M.S. 2015. The effects of motivational interviewing with the dual diagnosis population. Walden University. [Online] Available: https://www.semanticscholar.org/paper/The-Effects-ofMotivational-Interviewing-with-the-Moore/e7a944f8b42dfe8a7c4f73542f0db3fe32000229 [Accessed: 11/09/2019].

MOROJELE, N.K., KITLELI, N., NGAKO, K., KEKWALETSWE, C.T., NKOSI, S., FRITZ, K. \& PARRY, C.D.H. 2014. Feasibility and acceptability of a bar-based sexual risk reduction intervention for bar patrons in Tshwane, South Africa. SAHARA: Journal of Social Aspects of HIV/AIDS Research Alliance, 11(1):1-9.

ORGANISTA, K.C., MUÑOZ, R.F. \& GONZÁLEZ, G. 1994. Cognitive-behavioral therapy for depression in low-income and minority medical outpatients: Description of a program and exploratory analyses. Cognitive Therapy and Research, 18(3):241-259.

PARRY, C.D., MOROJELE, N.K., MYERS, B.J., KEKWALETSWE, C.T., MANDA, S.O., SORSDAHL, K., RAMJEE, G., HAHN, J.A. 2014. Efficacy of an alcohol-focused intervention for improving adherence to antiretroviral therapy (ART) and HIV treatment outcomes - a randomised controlled trial protocol. BMC Infectious Diseases, 14(1):500.

PETERSEN, R., ALBRIGHT, J., GARRETH, J.M., CURTIS, K. 2007. Pregnancy and STD prevention counselling using. An adaptation of motivational interviewing: A randomized controlled trial Volume 39, doi: $10.1363 / 3902107$

ROLLNICK, S., MILLER, W. R., \& BUTLER, C.C. 2007. Motivational interviewing in health care: Helping patients change behavior. New York: Guilford Press.

ROSSOUW, L., SEEDAT, S., EMSLEY, R.A., SULIMAN, S. \& HAGEMEISTER, D. 2013. The prevalence of burnout and depression in medical doctors working in the Cape Town Metropolitan Municipality community healthcare clinics and district hospitals of the Provincial Government of the Western Cape: a cross-sectional study. South African Family Practice, 55(6): 567 - 573.

SATRE, D.D., LEIBOWITZ, A., STERLING, S.A., LU, Y., TRAVIS, A. \& WEISNER, C. 2016. A randomized clinical trial of motivational interviewing to reduce alcohol and drug use among patients with depression. Journal of Consulting and Clinical Psychology, 84(7):571-579.

SÖDERLUND, L.L., NILSEN, P. \& KRISTENSSON, M. 2008. Learning motivational interviewing: Exploring primary health care nurses' training and counselling experiences. Health Education Journal, 67(2):102-109.

SÖDERLUND, L.L., MADSON, M.B., RUBAK, S. \& NILSEN, P. 2011. A systematic review of motivational interviewing training for general health care practitioners. Patient Education and Counselling, 84(1):16-26.

STORHOLM, E.D., OBER, A.J., HUNTER, S.B., BECKER, K.M., IYIEWUARE, P.O., PHAM, C. \& WATKINS, K.E. 2017. Barriers to integrating the continuum of care for opioid and alcohol use disorders in primary care: A qualitative longitudinal study. Journal of Substance Abuse Treatment, $83: 45-54$.

TACIA, L., BISKUPSKI, K., PHELEY, A. \& LEHTO, R.H. 2015. Identifying barriers to evidence- 
based practice adoption: A focus group study. Clinical Nursing Studies, 3(2):90.

VANBUSKIRK, K.A. \& WETHERELL, J.L. 2014. Motivational interviewing with primary care populations: a systematic review and meta-analysis. Journal of Behavioral Medicine, 37(4):768-780.

WESTRA, H.A. 2004. Managing resistance in cognitive behavioural therapy: The application of motivational interviewing in mixed anxiety and depression. Cognitive Behaviour Therapy, 33(4):161-175.

WESTRA, H.A. \& AVIRAM, A. 2013. Core skills in motivational interviewing. Psychotherapy, 50(3):273-278.

YAKOVENKO, I., QUIGLEY, L., HEMMELGARN, B.R., HODGINS, D.C. \& RONKSLEY, P. 2015. The efficacy of motivational interviewing for disordered gambling: Systematic review and metaanalysis. Addictive Behaviors, 43:72-82. 